\title{
Scale Up of Slurry Bubble Reactors
}

\author{
A. Forret ${ }^{1}$, J.M. Schweitzer ${ }^{1}$, T. Gauthier ${ }^{1}$, R. Krishna ${ }^{2}$ and D. Schweich ${ }^{3}$ \\ 1 IFP-Lyon, BP 3, 69390 Vernaison - France \\ 2 Department of Chemical Engineering, University of A msterdam, 1018 W V A msterdam - The $N$ etherlands \\ 3 LGPC-CNRS, ESCPE, 43, boulevard du 11 N ovembre, BP 2077, 69616 Villeurbanne - France \\ e-mail: ann.forret@ifp.fr -j-marc.schweitzer@ifp.fr - thierry.gauthier@ifp.fr - krishna@science.uva.nl - dsw@lobivia.cpe.fr
}

\begin{abstract}
Résumé - Extrapolation des réacteurs slurry - Les réacteurs à colonne à bulles trouvent de plus en plus d'applications dans l'industrie. Ils sont particulièrement appropriés pour mettre en œuvre des réactions très exothermiques, telles que la synthèse du méthanol ou la synthèse Fischer-Tropsch de conversion du gaz de synthèse en paraffines liquides. Les procédés industriels requièrent des réacteurs de gros volumes, dont le diamètre peut atteindre $10 \mathrm{~m}$, équipés d'échangeur de chaleur interne (tubes verticaux) afin de contrôler la température de réaction. La présente étude a pour objet la compréhension des effets de taille et de la présence des internes sur les caractéristiques hydrodynamiques pour contribuer à l'élaboration des règles d'extrapolation aux conditions industrielles des réacteurs slurry à partir d'expériences menées en maquettes froides.

Notre étude montre que l'intensité de la recirculation liquide augmente fortement avec le diamètre de la colonne alors que le taux de vide n'est que peu affecté. Deux méthodes sont proposées pour prédire l'effet de taille sur la vitesse liquide : une corrélation empirique tirée de la littérature ainsi qu'un modèle phénoménologique. Les tubes verticaux (simulant des échangeurs de chaleur) guident axialement la circulation liquide, favorisant le transport convectif et diminuant les fluctuations de vitesse. Le mélange du liquide est alors significativement affecté par la présence des internes. Il ne peut plus être décrit correctement par le modèle standard mono dimensionnel de dispersion axial. Un modèle bidimensionnel, prenant en compte le profil radial de la vitesse liquide ainsi que la dispersion axiale et radiale est donc développé pour représenter le mélange du liquide dans une colonne à bulles avec internes.
\end{abstract}

\footnotetext{
Abstract - Scale Up of Slurry Bubble Reactors - Bubble column reactors are finding increasing use in industrial practice. They are in particular appropriate to carry out highly exothermic reactions, such as methanol synthesis or Fischer-Tropsch synthesis of conversion of synthesis gas to liquid paraffins. Industrial process require important volumes of reactors, the reactor diameter can reach $10 \mathrm{~m}$. To control the reaction temperature, internal heat-exchange tubes (vertical tubes) are inserted inside the reactor. This study deals with the effects of scale and the presence of internals on hydrodynamic characteristics, for scale-up purposes based on experiments in cold mockups.

Our study shows that the liquid recirculation intensity depends strongly on the column diameter whereas the gas holdup is slightly affected. Two methods are proposed to predict scale effect on liquid velocity: an empirical correlation proposed in the literature and a phenomenological model. Internals guide liquid: the large scale recirculation increases but fluctuations of liquid velocity decrease. Therefore the mixing of liquid is significantly affected by the presence of internals and is not well described by the standard mono dimensional axial dispersion model. A two-dimensional model, taking into account a radially dependent axial velocity profile and both axial and radial dispersion, is therefore developed to describe the liquid mixing in a bubble column with internals.
} 


\section{NOTATIONS}

ADM Axial Dispersion Model

C local tracer concentration $\left(\mathrm{mol} / \mathrm{m}^{3}\right)$

$C^{L} \quad$ tracer concentration in liquid phase $\left(\mathrm{mol} / \mathrm{m}^{3}\right)$

$C_{1} \quad$ tracer concentration in the upflow liquid flow region $\left(\mathrm{mol} / \mathrm{m}^{3}\right)$

$\mathrm{C}_{2} \quad$ tracer concentration in the downflow liquid flow region $\left(\mathrm{mol} / \mathrm{m}^{3}\right)$

$\bar{C} \quad$ cross-sectional averaged tracer concentration $\left(\mathrm{mol} / \mathrm{m}^{3}\right)$

CSTR Continuous Stirred Tank Reactor

D column diameter (m)

$D_{a x} \quad$ liquid axial dispersion coefficient $\left(\mathrm{m}^{2} / \mathrm{s}\right)$

$D_{a x, I D}$ liquid axial dispersion coefficient determined by the one-dimensional ADM $\left(\mathrm{m}^{2} / \mathrm{s}\right)$

$D_{a x, 2 D}$ liquid axial dispersion coefficient determined by the two-dimensional model $\left(\mathrm{m}^{2} / \mathrm{s}\right)$

$D_{\text {rad,2D }}$ liquid radial dispersion coefficient determined by the two-dimensional model $\left(\mathrm{m}^{2} / \mathrm{s}\right)$

$d_{t} \quad$ diameter of vertical internals (m)

$H \quad$ height of measurement or sampling (m)

$H_{D} \quad$ aerated height (m)

$N \quad$ number of acquisition data points

$n_{t} \quad$ number of cooling tubes

$r \quad$ radial coordinate $(\mathrm{m})$

$S \quad$ column cross section area $\left(\pi \mathrm{D}^{2} / 4\right)\left(\mathrm{m}^{2}\right)$

$S_{\text {free }} \quad \begin{aligned} & \text { open cross section area or free surface } \\ & \left(\mathrm{m}^{2}\right)\end{aligned}\left(S-n_{t} \pi \frac{d_{t}^{2}}{4}\right)$

$u_{i} \quad$ instantaneous liquid velocity $(\mathrm{m} / \mathrm{s})$

$u_{\sigma}(r)=\sqrt{\frac{\sum_{i=1}^{N}\left(u_{i}(r)-V_{L}(r)\right.}{N}}$ r.m.s. fluctuation of the velocity $(\mathrm{m} / \mathrm{s})$

$U_{g} \quad$ effective superficial gas velocity $\left(Q_{g} / S_{\text {free }}\right)$ determined at pressure conditions prevailing just above the gas distributor $(\mathrm{m} / \mathrm{s})$

$V_{L}(r)=\frac{\sum_{i=1}^{N} u_{i}(r)}{N}$ time-averaged local axial liquid velocity $(\mathrm{m} / \mathrm{s})$

$V_{L}(0)$ time-averaged center-line liquid velocity or maximum upward velocity measured along column axis $(\mathrm{m} / \mathrm{s})$

$x \quad$ dimensionless radial coordinate $x=2 r / D$

$x_{i n v} \quad$ dimensionless radial coordinate at the flow reversal

$z \quad$ dimensionless axial coordinate $z=H / H_{D}$.

\section{G reek Letters}

$\begin{array}{ll}\varepsilon_{g} & \text { local gas holdup } \\ \bar{\varepsilon}_{g} & \text { global gas holdup }\end{array}$ $\varepsilon_{1} \quad$ gas holdup of the upflow liquid flow region

$\varepsilon_{2} \quad$ gas holdup of the downflow liquid flow region

$\mu_{L} \quad$ dynamic viscosity of the liquid (Pa.s)

$v_{t} \quad$ turbulent kinematic viscosity $\left(\mathrm{m}^{2} / \mathrm{s}\right)$

$\rho_{L} \quad$ liquid phase density $\left(\mathrm{kg} / \mathrm{m}^{3}\right)$

$\sigma \quad$ surface tension $(\mathrm{N} / \mathrm{m})$

$\Delta P \quad$ differential pressure $(\mathrm{Pa})$.

\section{IN TRO DUCTION}

There is considerable interest, both within academia and industry, on the hydrodynamics of bubble column reactors. This interest stems from the many practical applications, especially in emerging technologies for conversion of natural gas to transportation fuels (Krishna and Sie, 2000). Published studies on bubble column hydrodynamics have often been restricted to columns with small column diameters $D<0.5 \mathrm{~m}$ and without internal heat-exchange tubes.

We have undertaken a comprehensive study of the hydrodynamics (measurements of gas holdup, liquid velocity profile, axial dispersion) in three different columns with diameters $0.15,0.4$ and $1 \mathrm{~m}$ with and without internals. The overall objective of our study is to develop reliable methods for scaling up bubble column reactors to commercial scale which could range to $10 \mathrm{~m}$ in diameter and $40 \mathrm{~m}$ in height.

\section{SLURRY BUBBLE REACTOR}

\subsection{Industrial Background}

Slurry bubble column reactors are simple vertical cylindrical vessels with intense contact between gas, liquid and solid phases. In most applications, gas is the reactant, liquid is the product of reaction and solid is the catalyst. The "liquid + solid particles" suspension can be represented as an homogeneous fluid phase and is named slurry. The gas phase is dispersed into the slurry phase using specific gas distributors at the bottom of the column. A simplified representation of a slurry bubble column is shown in Figure 1 .

The main attractive features of slurry bubble columns are:

- A high liquid mixing which should provide homogeneous catalyst concentration and temperature distributions. Mixing and/or turbulence also favor mass and heat transfer.

- The use of small catalyst particle size (about $50 \mu \mathrm{m}$ ) which reduces intra-particle diffusion limitation.

- Easy catalyst addition and withdrawal from the reactor.

- Low pressure drop.

In particular, thanks to their high liquid mixing, slurry bubble column reactors are suitable for carrying out highly exothermic reaction, such as methanol synthesis or FischerTropsch synthesis (Fischer and Tropsch, 1921). In the 


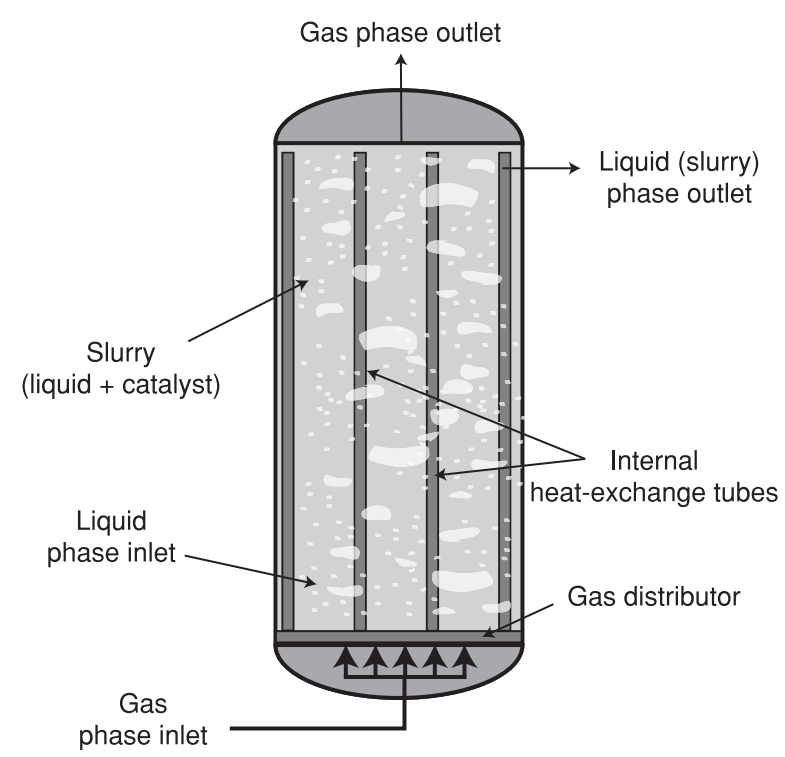

Figure 1

Slurry bubble column scheme.

Fischer-Tropsch process, the reacting gas is a mixture of hydrogen and carbon monoxide called synthesis gas or shortly syngas. The reaction is heterogeneously catalyzed using an iron or cobalt based catalyst. To produce gasoil like molecules, say $\mathrm{C}_{16} \mathrm{H}_{34}$, one has to evacuate $16 \times 165 \mathrm{~kJ}$ per mole of cetane. To remove heat from the reacting medium, a slurry reactor equipped with an immersed tubular heat exchanger is an appropriate reactor technology.

Nevertheless, these reactors present also some drawbacks:

- The high liquid mixing is detrimental for the conversion and could generate catalyst attrition.

- The separation of fine solid catalyst particles from liquid products is difficult.

- Slurry handling requires careful design to avoid plugging.

In addition, large gas throughputs are involved, requiring the use of large reactor diameter, typically 5-10 m. Reliable scale-up and design criteria are needed but are still lacking. Our study will therefore focus on the scale-up of hydrodynamics.

\subsection{Phenomenology of a Slurry Bubble Column}

The hydrodynamic behavior of bubble columns is strongly dependent on the flow regime (Deckwer et al., 1980). Commercial reactors are usually operated at high gas velocity, i.e. in the churn turbulent regime. A brief description of the flow regimes encountered in bubble columns and of flow regime transitions is presented below.

Gas holdup regimes in slurry bubble columns are generally investigated by measuring or watching the evolution of the bubble characteristics (bubble shape, size and velocity) as a function of operating conditions (gas flowrate, solid concentration, particle diameter, etc.). Different regimes can be distinguished as the gas velocity is gradually increased. A qualitative representation of the observed flow regimes for the experimental range of columns and superficial gas velocities is shown in Figure 2.

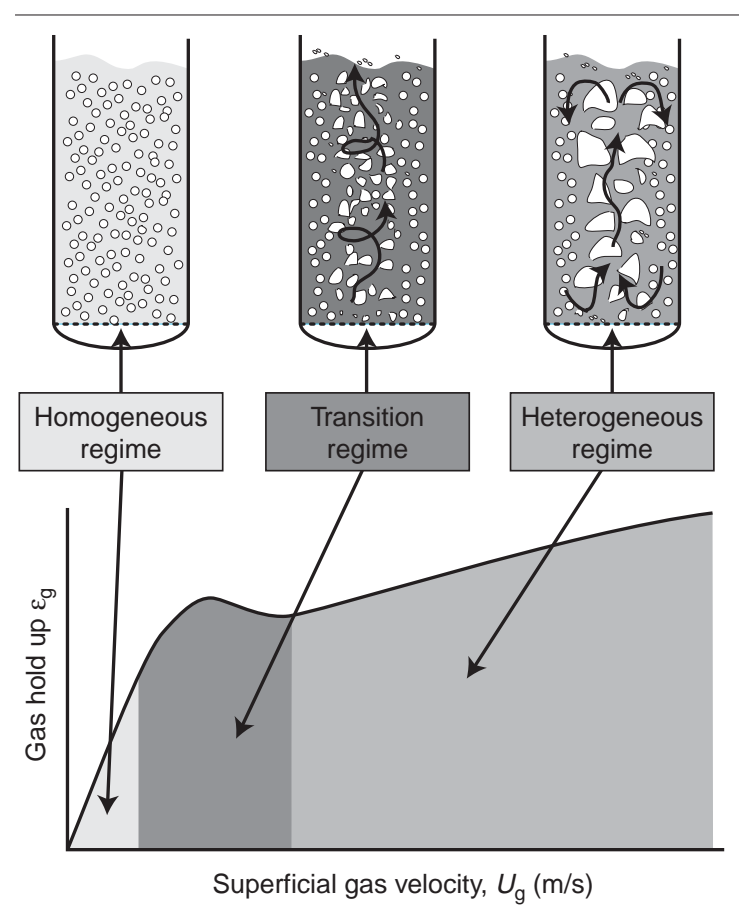

Figure 2

Qualitative representation of the different flow regimes (Urseanu, 2000).

The regime depends on design parameters (distributor design, column diameter), operating parameters (superficial gas and liquid velocities) and physical properties (viscosity, surface tension, density and coalescing nature of the liquid phase). Three main regimes can be distinguished:

- The homogeneous regime or bubbly regime or dispersed regime, where the gas holdup increases markedly with the superficial gas velocity. Bubble size is roughly uniform (Krishna, 2000), and radial profile of gas holdup is nearly flat. In this low gas velocity range, the distributor design affects gas holdup (Luo et al., 1999).

- The transition regime where gas holdup may go through a maximum.

- The heterogeneous regime or churn-turbulent regime or coalesced bubble regime, where bubble coalescence and breakage is significant. Roughly speaking, the breakage and coalescence mechanism is responsible for two classes of bubbles:

. small bubbles similar to those observed in the homogeneous regime, their volume fraction is close to that observed at the beginning of the transition regime; 
. large bubbles that move quickly upwards as vapor bubbles in a boiling liquid. The radial profile of gas holdup shows a maximum at the column centre-line, and holdup is nearly zero at the wall (Krishna and Ellenberger, 1996; Krishna et al., 1996).

For completeness, the slug regime can be found when superficial gas velocity is increased further. The slug regime is highly unstable. The gas passes through the liquid in intermittent plugs while the liquid near the wall continuously pulses up and down. This regime is generally limited to columns of small diameter.

The domain of industrial interest concerns in particular the heterogeneous regime, characterized by high mass and heat transfers.

\section{STATE OF THE ART}

Most of the mechanical energy dissipated in the reactor comes from the gas fed at the bottom of the column. Catalyst particles are in suspension in the mixed liquid phase. It is well-known from literature that at sufficient gas throughput, in the churn-turbulent regime, liquid flows upwards in the central core region and when bubbles disengage at the top, liquid returns down in the wall region (see Fig. 3).

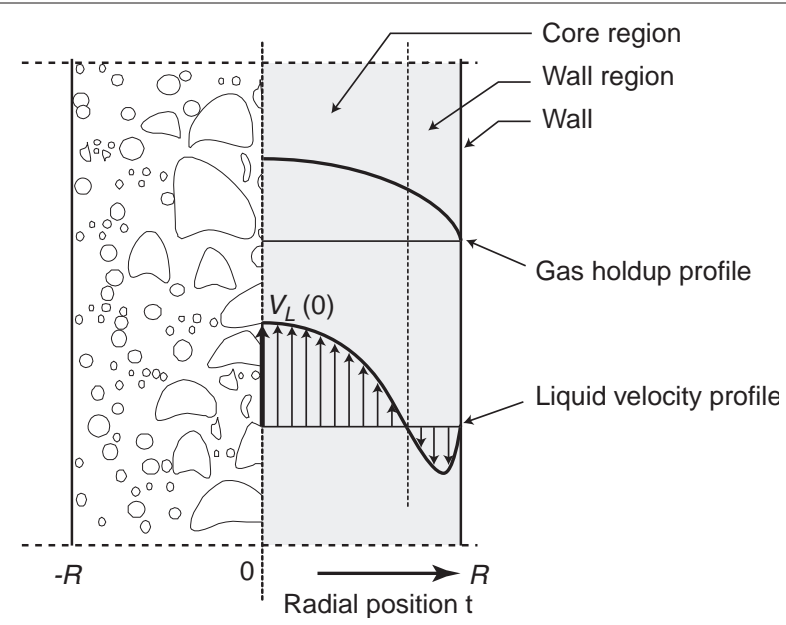

Figure 3

Gas holdup and liquid velocity profiles in churn turbulent regime.

This flow pattern has been often observed generally in small columns $(D<0.5 \mathrm{~m})$, without internals and with the air-water system. However little or no studies are available at larger scale, for scale up purpose of this phenomena.

\subsection{Literature Data}

Most published data are obtained in small columns, with $H_{D} / D$ ratio larger than 10 . Nevertheless, it is interesting from an industrial point of view to study lower $H_{D} / D$ ratios.
Parasu Veera and Joshi (2000) reported that for a ratio $H_{D} / D$ ratio above $4-5$, the global gas holdup is not affected by this ratio. In this condition $\left(H_{D} / D>5\right)$, clear trends are reported in the open literature. Numerous authors (Joshi et al., 1998; Shah et al., 1982) reported that, in the heterogeneous regime, the global gas holdup is independent of the column diameter when the latter is greater than $0.15 \mathrm{~m}$ (except for highly viscous solutions). In addition, all papers dealing with column size reported that liquid recirculation and backmixing increase strongly with column diameter D (Krishna, 2000; Baird and Rice, 1975; Towell et al., 1972).

Nevertheless, data reported in the open literature are scattered. Let us take the example of the centre-line liquid velocity $V_{L}(0)$ predicted by various empirical correlations proposed in the literature as a function of $D$ (see Fig. 4).

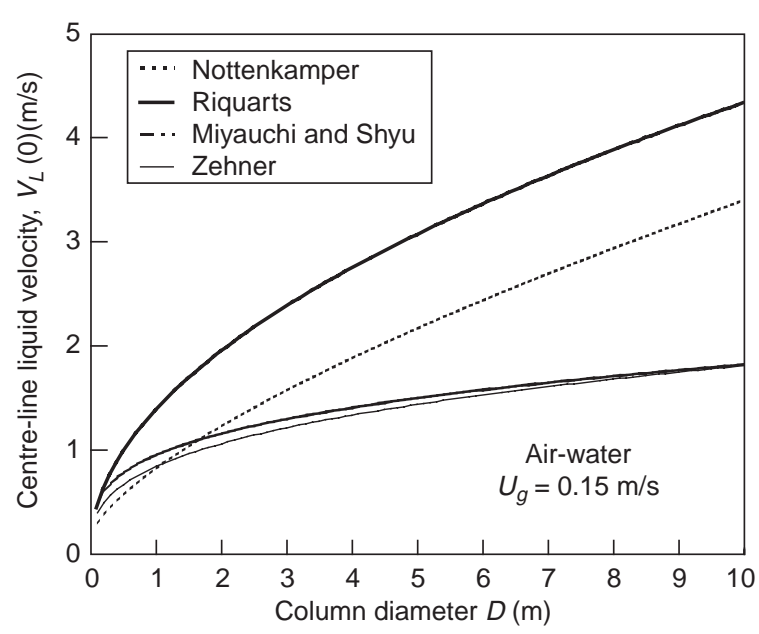

Figure 4

$V_{L}(0)$ predicted by various literature empirical correlations as a function of $D$.

Figure 4 shows that for a given superficial gas velocity $\left(U_{g}=0.15 \mathrm{~m} / \mathrm{s}\right.$ ) with the air-water system, the range predicted for the centre-line liquid velocity $V_{L}(0)$ varies from 1.5 to $4.5 \mathrm{~m} / \mathrm{s}$ for a column diameter of $10 \mathrm{~m}$. We should remind that these correlations are generally based on experiments performed for $D<0.5 \mathrm{~m}$.

Only a few studies about internals in bubble columns have been found in the open literature. The most relevant studies are those of Berg et al. (1995) and Bernemann (1989) who reported an increase of the liquid recirculation intensity in the presence of internals.

\subsection{Modeling Approach}

From a modeling point of view, different approaches may be followed to describe hydrodynamics of a slurry bubble column. The approach commonly used in Chemical Engineering is a global one that considers the slurry bubble 
column "plug flow-dispersion". This means that one assumes that gas is plug flow and liquid partially mixed. The degree of liquid mixing is characterized by the axial dispersion coefficient Dax determined with the standard mono-dimensional Axial Dispersion Model (ADM).

Hydrodynamics can also be described by phenomenological models, such as Ueyama and Miyauchi's (1979) or Rice and coworkers' (Geary and Rice, 1992) models based on radial momentum balance.

Computational fluid dynamics (CFD) has emerged as a powerful tool to analyze the flow pattern in bubble columns. Over the past twenty years, there has been good development in understanding flow structure. Joshi (2001) has reviewed the developments in modeling of the two-phase flow in detail. In spite of a large number of publications concerning flow pattern in bubble columns, many important issues still remain unsolved. The major issues are:

- closure problem;

- proper description of interface momentum and energy transfer;

- modeling of radial movement of bubbles;

- identification of coherent turbulent structures and quantification of their contributions to the transport phenomena;

- description of transient and three dimensional flow pattern, etc.

Only after proper validation of CFD models with laboratory-scale data will it be possible to use them as dependable scale-up tools in the future. Because of a lack of experimental local data, it is still difficult to validate closure laws in CFD.

\section{METHO DO LOGY OF THE STUDY}

For industrial scale-up purpose, the global approach of "plug flow-dispersion" is retained, as well as phenomenological models. For this kind of models, the following global characteristics should be determined:

- gas holdup;

- and center-line liquid velocity and axial dispersion coefficient Dax that characterized the degree of liquid mixing.

Our study therefore focuses on the experimental determination of these characteristics as a function of scale and in the presence or not of internals. For completeness, we will measure liquid velocities.

\section{EXPERIMENTAL APPRO ACH}

\subsection{Fluid System and Apparatus}

\subsubsection{Fluid System}

Effects of slurry properties should be taken into account to scale up hydrodynamics in a laboratory unit to industrial reactor. Fluids used for our experiments at ambient conditions are chosen to represent as well as possible standard FischerTropsch wax at industrial conditions. Table 1 reports physical properties of laboratory gas-liquid systems at ambient temperature and pressure, and the standard Fischer-Tropsch wax properties at industrially relevant operating conditions (Bukur et al., 1987; Patel et al., 1990).

It is difficult to represent simultaneously density, viscosity and surface tension. To study effects of scale and internals on hydrodynamics, we choose in particular the system airwater. Note that experiments are also performed with other systems, such as heptane, but are not reported in the present paper.

\subsubsection{Apparatus}

To determine the sensitivity of hydrodynamic characteristics to column diameter and to be able to predict their order of

TABLE 1

Physical properties of various gas-liquid systems at ambient conditions and expected wax properties at industrial operating conditions

\begin{tabular}{|c|c|c|c|c|c|}
\hline & & $\begin{array}{c}\text { Temperature } \\
T(\mathrm{~K})\end{array}$ & $\begin{array}{c}\text { Density } \\
\rho_{L} /\left(\mathrm{kg} / \mathrm{m}^{3}\right)\end{array}$ & $\begin{array}{c}\text { Dynamic viscosity } \\
\mu_{L} /(\mathrm{mPa} . \mathrm{s})\end{array}$ & $\begin{array}{c}\text { Surface tension } \\
\sigma /(\mathrm{N} / \mathrm{m})\end{array}$ \\
\hline \multirow{2}{*}{ Ambient conditions } & Air-water & 293 & 1000 & 1 & 0.073 \\
\hline & Nitrogen-heptane & 293 & 690 & 0.41 & 0.020 \\
\hline \multirow{4}{*}{ Industrial conditions } & Paraffin wax & $\begin{array}{l}493 \\
533\end{array}$ & $\begin{array}{l}690 \\
670\end{array}$ & $\begin{array}{l}4.0 \\
2.0\end{array}$ & $\begin{array}{l}0.024 \\
0.021\end{array}$ \\
\hline & FT-300 wax & $\begin{array}{l}503 \\
538\end{array}$ & $\begin{array}{l}706 \\
681\end{array}$ & $\begin{array}{l}3.6 \\
2.7\end{array}$ & \\
\hline & Sasol wax & $\begin{array}{l}473 \\
538\end{array}$ & $\begin{array}{l}701 \\
655\end{array}$ & $\begin{array}{l}2.9 \\
2.0\end{array}$ & \\
\hline & Mobil waxes & $\begin{array}{l}473 \\
533\end{array}$ & 716 & $\begin{array}{l}3.8 \\
3.4\end{array}$ & $0.021-0.027$ \\
\hline
\end{tabular}


magnitude at large scale, measurements should be performed in different column sizes and with diameter as large as possible with respect to experimental constraints. In the present study we could use several columns with diameters: $D=0.15,0.40$ and $1 \mathrm{~m}$ (Fig. 5).

To be as close as possible to industrial conditions and to simulate the presence of vertical cooling tubes, internals were inserted in the bubble columns, with the following configuration: 56 tubes, each $63 \mathrm{~mm}$ in diameter, arranged in a square pitch of $108 \mathrm{~mm}$.

\subsection{Technical Means}

To determine the hydrodynamic characteristics in a bubble column, the following technical means are used.

\subsubsection{Gas Holdup}

In the present work, the visual technique is used to measure the global gas holdup. This method consists in measuring by visual observations the expanded height of the liquid:

$$
\bar{\varepsilon}_{g}=1-\frac{H_{0}}{H_{D}}
$$

This technique is very easy and is completed by the measure of holdup in an aerated liquid layer by pressure difference: the mean gas holdup is determined by measuring static pressure at the column wall (assuming that the variation of gas holdup in axial direction depends only slightly on the acceleration and friction processes, Nottenkämper et al., 1983). a)

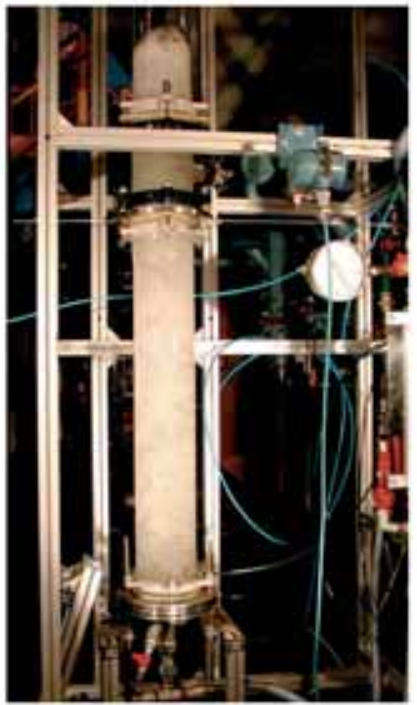

$D=0.15 \mathrm{~m}$

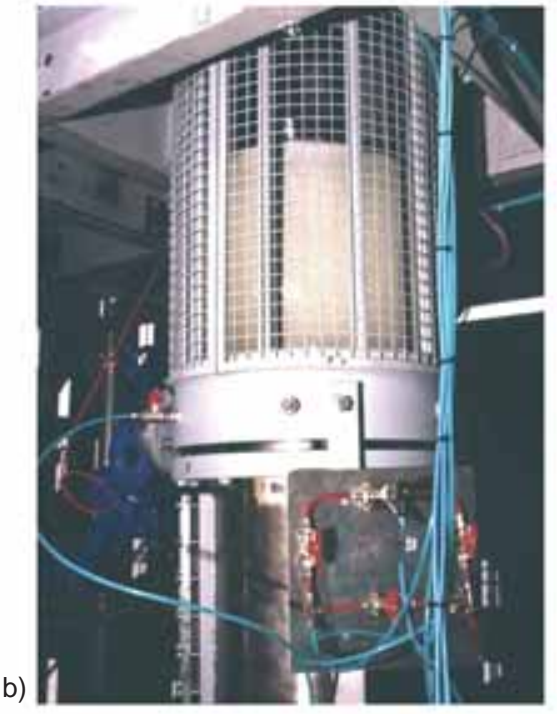

$D=0.40 \mathrm{~m}$

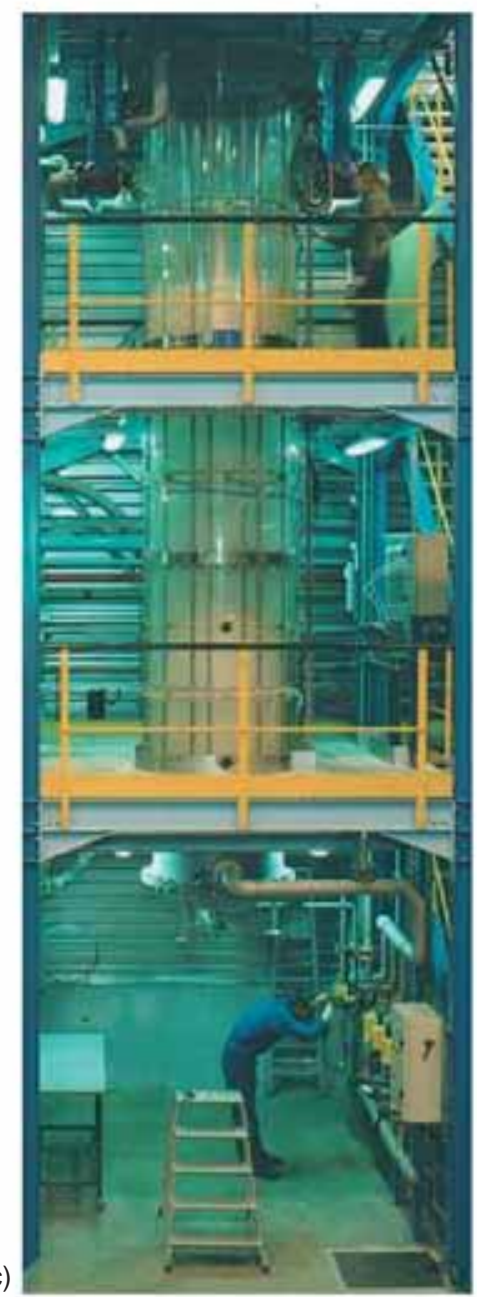

$D=1 \mathrm{~m}$

Figure 5

Columns used of different diameters: a) $0.15 \mathrm{~m}$, b) $0.40 \mathrm{~m}$ and c) $1 \mathrm{~m}$. 


\subsubsection{Liquid Velocity}

In the present work, liquid velocities are measured by a modified Pavlov tube based on the work of Hills (1974); see Forret et al. (2003). This Pavlov tube is a stainless tube in which two opposite holes are drilled (see Fig.6). A separation between the two holes divides the tube in two parts. One part is connected to the high-pressure branch of a transducer and the other to the low-pressure branch.

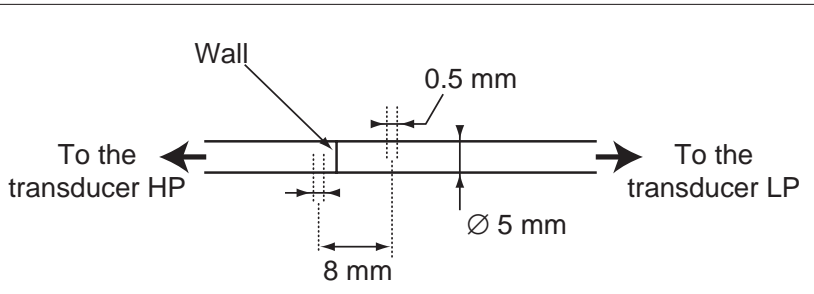

Figure 6

Pavlov tube.

The differential pressure obtained between the two opposite holes is directly linked with the time-averaged axial liquid velocity $V_{L}$. The measuring time for each acquisition is 5 minutes with a frequency of $50 \mathrm{~Hz}$ :

$$
V_{L}(r)=\frac{\sum_{i=1}^{N} u_{i}(r)}{N} \text { with } u_{i}=\left\{\begin{array}{l}
\sqrt{\frac{2 . \Delta P_{i}}{\rho_{L}}} \text { if } \Delta P_{i} \geq 0 \\
-\sqrt{\frac{-2 . \Delta P_{i}}{\rho_{L}}} \text { if } \Delta P_{i}<0
\end{array}\right.
$$

Figure 7 shows the signal of differential pressure measured: the velocity is quite fluctuating. Indeed the flow in a bubble column seems visually quite chaotic. Thanks to this technical mean, we determine the instantaneous liquid velocity $u_{i}$ and the time-averaged velocity $V_{L}$. We can therefore calculate the r.m.s. fluctuation of the velocity $u_{\sigma}(r)$ :

$$
u_{\sigma}(r)=\sqrt{\frac{\sum_{i=1}^{N}\left(u_{i}(r)-V_{L}(r)\right)^{2}}{N}}
$$

The Pavlov tube used was tested in a calibration bench. The bench used is a $50 \mathrm{~mm}$ vertical tube in which water and air can flow axially at given flowrates. It is possible to introduce a Pavlov tube in the bench through two diametrically opposed holes. The radial liquid profiles were measured by moving the tube along the column radius. Even with a gas holdup of $25 \%$, the measured liquid velocity with the Pavlov tube is reliable within an error of $10 \%$, which is quite reasonable (Forret et al., 2003). Note that the Pavlov tube technique has numerous advantages: easy construction and calibration, it is appropriate to different liquids and adaptable to different column sizes.

\subsubsection{Liquid Mixing}

For the determination of the liquid phase residence time distribution, a solution of potassium nitrate $\mathrm{KNO}_{3}$ is used as a tracer. The solution was injected into the batch liquid phase above the aerated height. Tracer evolution in the column is followed by conductivity measurement. Conductivity values are directly proportional to tracer concentration.

To avoid problems of in situ conductivity measurement (noise in the signal due to the fact that bubbles can be trapped between the two electrodes of the conductivity cell), samples are taken every second at a same height in the $1 \mathrm{~m}$ diameter

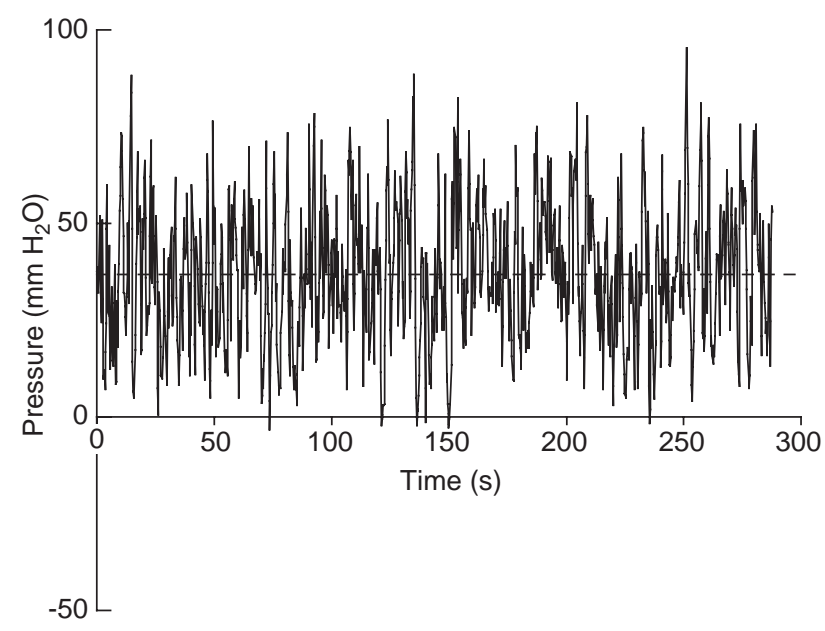

Figure 7

Pavlov tube signal.

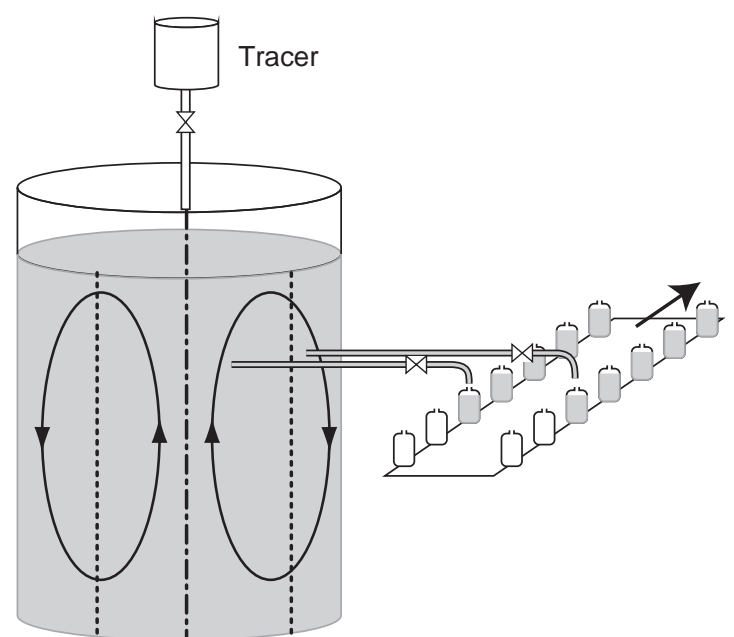

Figure 8

Dual sampling method. 
column. Conductivity of each sample is then measured. Sampling is performed at two radial positions (one in the middle of the upflow liquid flow region, the other in the middle of the downflow liquid flow region) (see Fig. 8).

The two sampling tubes have the same length in order to keep the same liquid crossing time in each tube.

\section{EXPERIMENTAL RESULTS}

\subsection{Flow Structure of the Stabilized Region of a Bubble Column}

To obtain "standard" data, as weakly affected as possible by the distributor region, the measurements are performed in the region we call "stabilized region": say about 1 diameter at least above the gas distributor and 1 diameter below the free surface, with aerated heights $H_{D}$ at least 5 times the column diameter $D$. Figure 9a shows that if local gas holdup values are normalized with respect to global gas holdup, the radial distribution $\varepsilon_{g}(x) / \bar{\varepsilon}_{g}$ is independent of the column diameter $D$ up to $1 \mathrm{~m}$, even in the presence of internals. In the same way, the radial profiles of liquid velocity normalized by the centre-line liquid velocity (measured along the axis) $V_{L}(x) / V_{L}(0)$ do not depend on scale (Fig. 9b).

Our results follow the same similar profile found early by Schweitzer et al. (2001), based on experiments performed in smaller columns $(D \leq 0.4 \mathrm{~m})$ without internals:

$$
\begin{array}{r}
\varepsilon_{g}(x)=\bar{\varepsilon}_{g}\left[-1.7889\left(x^{6}-1\right)+1.228\left(x^{4}-1\right)\right. \\
\left.-0.939\left(x^{2}-1\right)\right] \text { with } x=r / R
\end{array}
$$

Thus, only the value of the global gas holdup $\bar{\varepsilon}_{g}$ is necessary to determine the complete radial gas holdup profile. Concerning liquid flow, the instantaneous liquid recirculation in a bubble column is very complex and visually seems to be quite chaotic. Nevertheless the time-averaged liquid flow pattern proves to be quite organized: an upward flow in the centre and a downward flow near the wall. In addition we observe that the flow reversal (boundary between the upward flow in the core region and the downward flow near the wall) occurs at a dimensionless radial coordinate $x_{i n v}$ of about 0.7 . This means that the upflow region takes up $70 \%$ of the radius, in other words $50 \%$ of the cross-sectional area. This result is in agreement with numerous authors (Hills, 1974; Nottenkämper et al., 1983; Krishna, 2000, Urseanu, 2000, etc.): this gives support to the measurement technique we used and enable us to extend the validation of Equation (4) to larger columns ( $D$ up to $1 \mathrm{~m}$ ) even in the presence of internals. The normalized liquid velocity profile in the stabilized region of a bubble column can be written as follows:

$$
V_{L}(x)=\frac{V_{L}(0)}{a-c}\left[a \cdot \exp \left(-b \cdot x^{2}\right)-c\right]
$$

with $\mathrm{a}=2.976, \mathrm{~b}=0.943$ and $\mathrm{c}=1.848$ (parameters determined at ambient conditions, in the stabilized region, for $D$ up to $1 \mathrm{~m}$ with $H_{D} / D>5$ and $U_{g}>0.10 \mathrm{~m} / \mathrm{s}$ ).

Therefore, the centre-line liquid velocity $V_{L}(0)$ is a key parameter in describing the liquid circulation of bubble columns. Indeed, if we know only the value of $V_{L}(0)$, we are able to deduce with Equation (5) the complete radial velocity profile. Thus, the present experimental work is in most cases restricted to the measurement of global gas holdup $\bar{\varepsilon}_{g}$ and center-line liquid velocity $V_{L}(0)$.
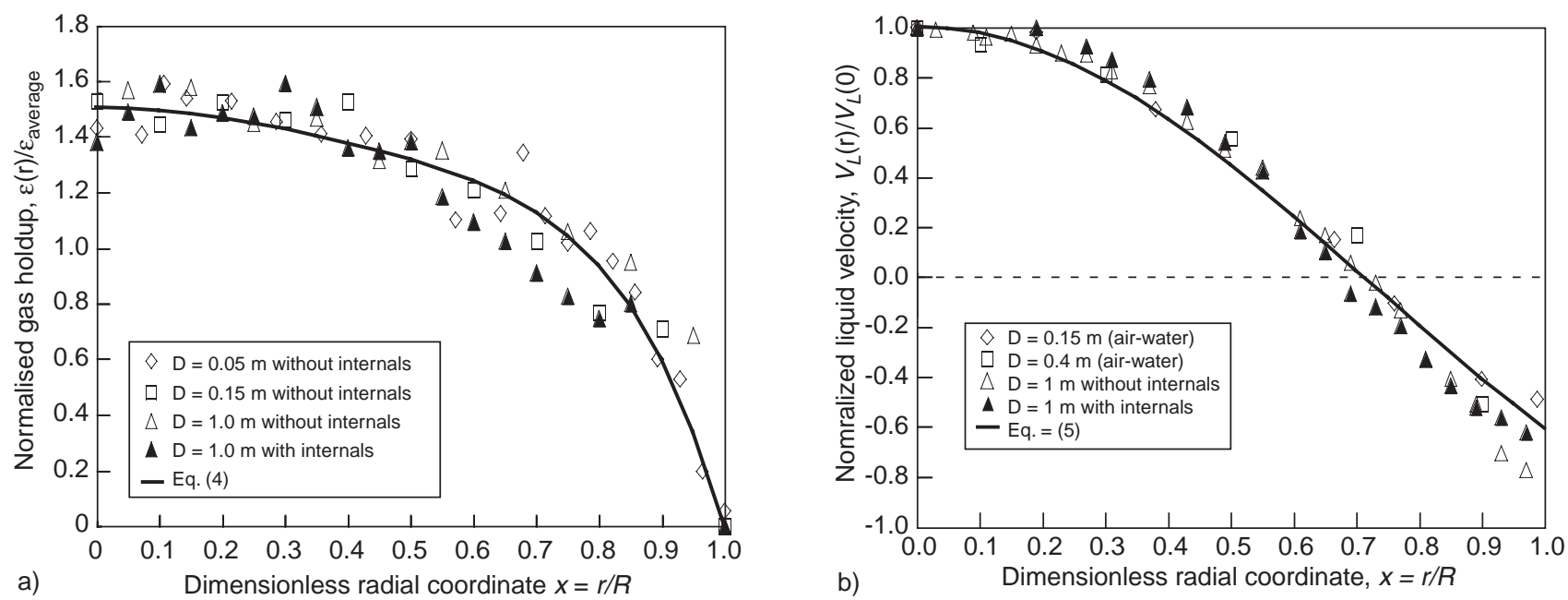

Figure 9

Normalized profiles of a) gas holdup $\varepsilon_{g}(x) / \bar{\varepsilon}_{g}$ and b) liquid velocity $V_{L}(x) / V_{L}(0)$ in the stabilized region for different $D$ up to 1 m with $H_{D} / D>5$ and $U_{g}>0.10 \mathrm{~m} / \mathrm{s}$. 


\subsection{Liquid Mixing in a Bubble Column}

From a modeling point of view, the liquid mixing can simply be characterized by an axial dispersion coefficient, determined in this work by the dual-sampling method detailed above in $\S 4.2 .3$. As the cross section of the upflow liquid flow region is equal to the cross section of the downflow liquid flow region and according to the assumption that the tracer concentration is homogeneous in all the cross section of the upflow $\left(C_{1}\right)$ or downflow $\left(C_{2}\right)$ liquid flow region, the average tracer concentration is calculated as following:

$$
\bar{C}=\frac{\left(1-\varepsilon_{1}\right) C_{1}+\left(1-\varepsilon_{2}\right) C_{2}}{2\left(1-\bar{\varepsilon}_{g}\right)}
$$

where $\varepsilon_{1}$ and $\varepsilon_{2}$ (respectively $C_{1}$ and $C_{2}$ ) are the gas holdups (respectively concentrations) in the upflow and downflow regions. Due to the short time needed for the mixing of the tracer (few seconds), averaging of three dual samplings per cross section are performed for each operating condition, at different height elevations. Then, a mono-dimensional dispersed-plug-flow model (axial dispersion model, ADM) is applied in order to determine the axial dispersion coefficient.

The dual sampling method enables us to take simultaneously samples near the wall and near the center. Indeed, it is very important to consider different radial locations, in order to average the tracer concentration on the considered cross section. Figure 10 shows the dimensionless tracer concentration curves (ratio of the average tracer concentration $\bar{C}$ to the final homogeneous concentration all over the column), obtained at different dimensionless radial positions $x$ (open symbols) in the column of $1 \mathrm{~m}$ in diameter.
We observe that these curves are quite different. Only the global result obtained by average on the cross section can be interpreted by the mono-dimensional axial dispersion model. Figure 10 shows the cross-sectional average over simultaneous withdrawals at two radial positions (black squares, $x=0.35$ and 0.85 ) corresponding to Equation (6), and over four radial positions (black diamonds, $x=0,0.3,0.6$ and $0.95)$. The average obtained over two or four withdrawals are roughly the same: this gives support to the average deduced from Equation (6). Moreover, we have verified that the averaged tracer concentration is independent of the injection mode.

\subsection{Scale Effect on Flow Structure}

Let us first consider gas holdup as a function of superficial gas velocity $U_{g}$ for three column diameters using the airwater system with an aerated height to diameter ratio $H_{D} / D$ greater than 5 . The global gas holdup $\bar{\varepsilon}_{g}$ measured by visual method as a function of $U_{g}$ is presented in Figure 11.

Global gas holdup obtained in the columns of $0.4 \mathrm{~m}$ and $1 \mathrm{~m}$ diameter are quite similar, and only slightly different with the column of $0.15 \mathrm{~m}$ diameter at low gas velocity. In fact in columns of smaller diameter than $0.15 \mathrm{~m}$ with airwater system, it has been observed that the wall effect cannot be totally neglected. Therefore, the global gas holdup is independent of scale as long as the column diameter is above $15 \mathrm{~cm}$; this result is in agreement with the conclusion reached by Joshi et al. (1998): it gives support to our approach and validates this conclusion for column diameters up to $1 \mathrm{~m}$.

Figure 12 shows center-line liquid velocity $V_{L}(0)$ as a function of $U_{g}$ for different diameters.

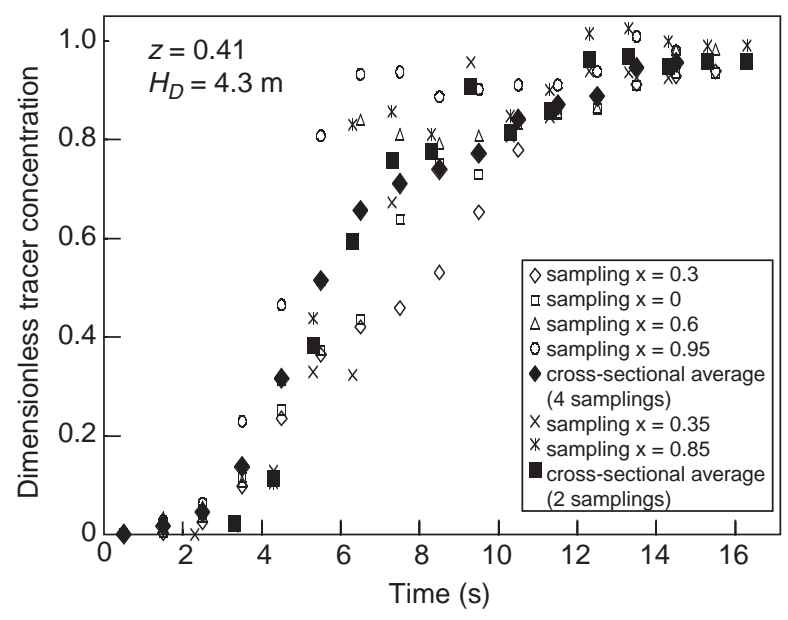

Figure 10

Cross-sectional averaged tracer concentration over two and four radial positions.

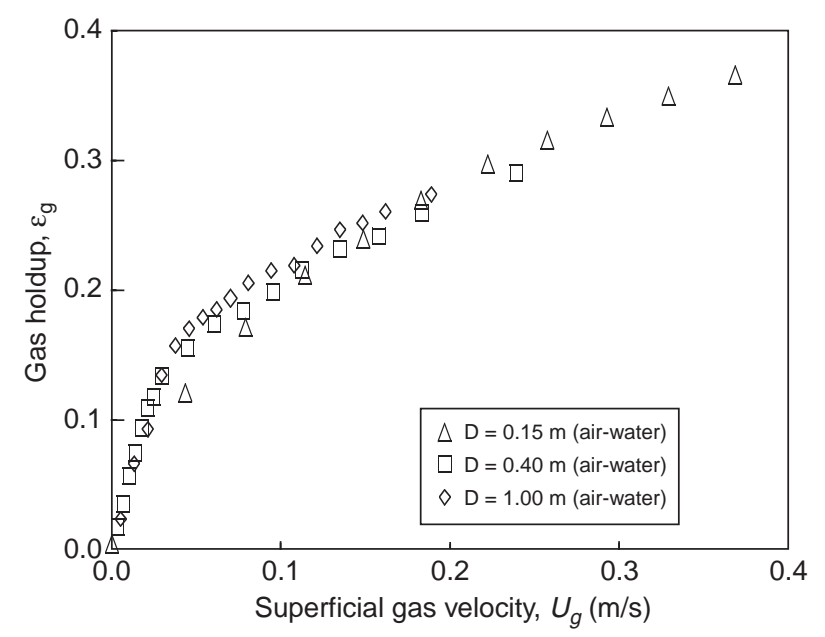

Figure 11

Global gas holdup as a function of $D$. 


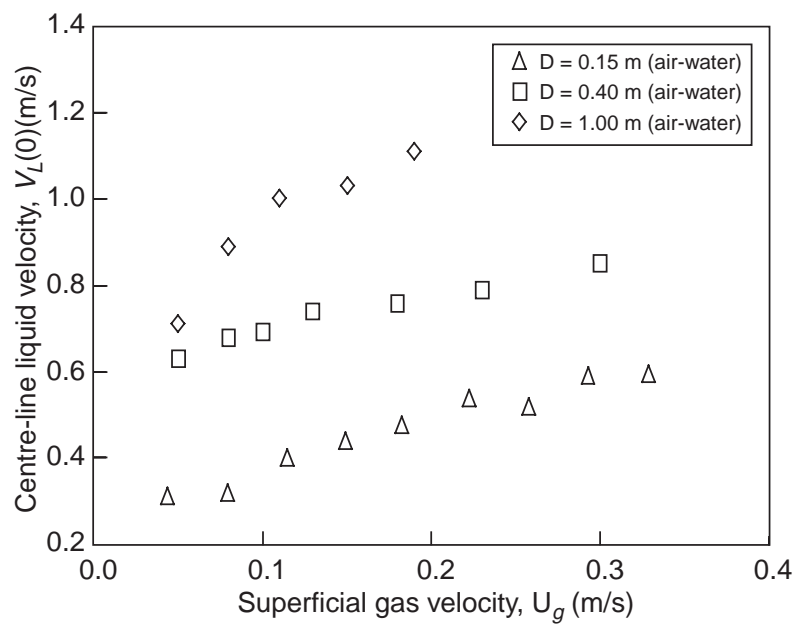

Figure 12

$V_{L}(0)$ as a function of $U_{g}$ for $D=0.15,0.40$ and $1 \mathrm{~m}$.

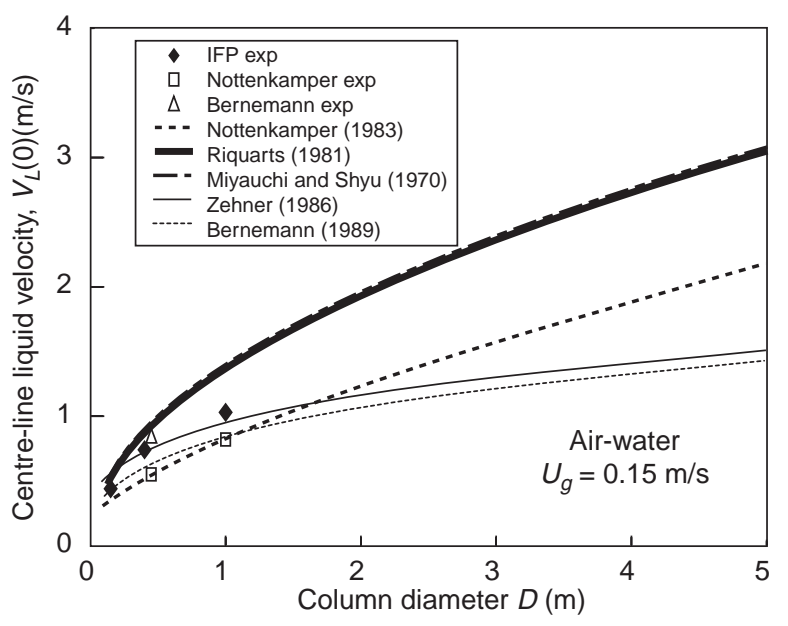

Figure 13

$V_{L}(0)$ as a function of $D$ compared with empirical correlations.
Figure 12 shows that $V_{L}(0)$ increases strongly with scale. For operation at $U_{g}=0.20 \mathrm{~m} / \mathrm{s}$, we note that $V_{L}(0)$ is higher than $1 \mathrm{~m} / \mathrm{s}$ in the column of $1 \mathrm{~m}$ diameter, which is more than twice the value obtained in the column of $0.15 \mathrm{~m}$ diameter.

\section{Modeling of Scale Effect on Liquid Recirculation}

The knowledge of the centre-line liquid velocity is important to determine the whole liquid velocity profile (see Fig. 9). Figure 13 compares centre-line liquid velocities as a function of column diameter with empirical correlations proposed in the literature.

Comparison with published correlations shows that extrapolation is still risky. Figure 13 shows that literature provides two sets of correlations predicting centre-line liquid velocities as a function of column diameter. Experimental data obtained in columns of diameters up to $1 \mathrm{~m}$ enable to discriminate among them. The lower curves (Miyauchi and Shyu, 1970; Nottenkämper, 1983; Zehner, 1986) seem the most appropriate correlations which give a range of velocities at large scale of $1.5-2 \mathrm{~m} / \mathrm{s}$ for a column of $5 \mathrm{~m}$ diameter with air-water system. The simplest way to predict $V_{L}(0)$ at large scale in the stabilized region is the use of Miyauchi and Shyu (1970) correlation given by:

$$
V_{L}(0)=2.47 \cdot U_{g}^{0.5} \cdot D^{0.28}
$$

This correlation takes only into account column diameter and superficial gas velocity, the two most relevant parameters.

These previously presented curves in Figure 13 reflect empirical correlations. It is also interesting to look at a more physical approach. A simplified one-dimensional two-fluid model has been widely used by various researchers (Miyauchi and Shyu, 1970; Ueyama and Miyauchi, 1979; Kojima et al., 1980, Riquarts, 1981; Kawase and Moo-Young, 1989; Devanathan, 1991) to obtain the liquid recirculation velocity profile. The differences among the models arise from the different types of constitutive equations that are used for closures such as expressions for eddy viscosity, Prandtl's mixing length or Reynolds shear stress. Based on the Ueyama and Miyauchi's work (1979), we tried to describe the liquid recirculation with a simplified 1-D model using a turbulent viscosity correlation. This correlation has been refined and validated with our experimental data for column diameters up to $1 \mathrm{~m}$.

$$
v_{t}=0.036 \cdot D^{1.6} U_{g}^{0.11}
$$

The strong influence of the column diameter $D$ is apparent in the 1.6 power. Figure 14 shows the radial profiles of the liquid velocity $V_{L}(r)$, experimentally measured (open symbols) and predicted by the model (continuous lines) for the three columns for $U_{g}=0.13-0.15 \mathrm{~m} / \mathrm{s}$ with the air-water system.

$V_{L}(r)$ for air-water system is predicted quite well by the present model. Scale-up trend on liquid recirculation is therefore assessed with reasonable accuracy.

\subsection{Scale Effect on Mixing Pattern}

To complete this study about liquid flow pattern, let us compare results obtained in the $1 \mathrm{~m}$ diameter column concerning the axial dispersion coefficient $D_{a x, 1 D}$, obtained relating to the well-known mono-dimensional axial dispersion model. For each superficial gas velocity, three dual samplings have been performed for three different distances between the sampling position and the free surface (see Fig. 15). 


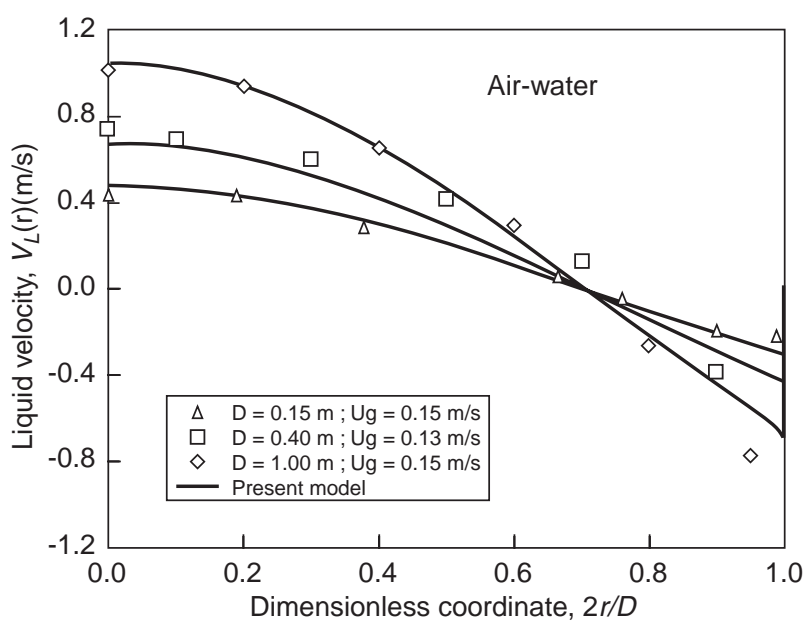

Figure 14

Radial profiles of liquid velocity compared with recirculation model for different column diameters with air-water system.

Figure 15 shows that the same axial dispersion coefficient enables to describe the tracer concentration measured at various height elevations: the axial dispersion model is therefore appropriate to describe the experiments. Finally, to know whether $D_{a x, 1 D}$ is a relevant parameter, it is necessary to check that a single coefficient value enables to simulate the tracer curves at different elevations. Otherwise the axial dispersion model is questionable.

Identical tracer experiments have been performed in columns of $0.15,0.4$ and $1 \mathrm{~m}$ diameter to determine axial dispersion coefficients. Figure 16 shows $D_{a x, 1 D}$ as a function of $D$ at $U_{g}=0.20 \mathrm{~m} / \mathrm{s}$.
Analogous to $V_{L}(0)$ (see Fig. 13), the axial dispersion coefficient is found to increase strongly with column diameter. Figure 16 compares our experimental results with correlations proposed in the literature and experimental data obtained by Wendt et al. (1984) and Krishna et al. (1999). Figure 16 shows that present results are consistent with literature data for column diameters below $0.4 \mathrm{~m}$. The comparison with correlations (Towell and Ackerman, 1972; Miyauchi et al., 1981; Riquarts, 1981) shows that most of them tend to underestimate $D_{a x, I D}$ at large scale for $U_{g}=0.20 \mathrm{~m} / \mathrm{s}$ (except Miyauchi et al., 1981). This can be explained by the local measurement made by many authors. We have shown that local measurements are not appropriate in large diameter columns because radial mixing becomes less efficient when the diameter increases. According to Figure 16, the most relevant empirical correlation is the one proposed by Miyauchi et al. (1981) described by Equation (9) which is in good agreement with our experimental data, for $D$ up to $1 \mathrm{~m}$ in the churn turbulent regime.

$$
D_{a x, 1 D}=D^{3 / 2} U_{g}^{1 / 4}\left(0.291+\frac{0.341}{\left(1-0.54 U_{g}^{1 / 2}\right)^{2}}\right)
$$

The one-dimensional ADM is a simple tool, easy to use, although its capability to describe two-phase flows with large degrees of backmixing, such as those in bubble columns is somewhat questionable (Wen and Fan, 1975; Levenspiel and Fitzgerald, 1983). To better describe experimental trends in large columns, for $D \geq 1 \mathrm{~m}$ in which radial concentration gradients are observed, we attempt a more detailed model. A two-dimensional (2-D) model was therefore developed to account for the radial dependence of the axial velocity (large

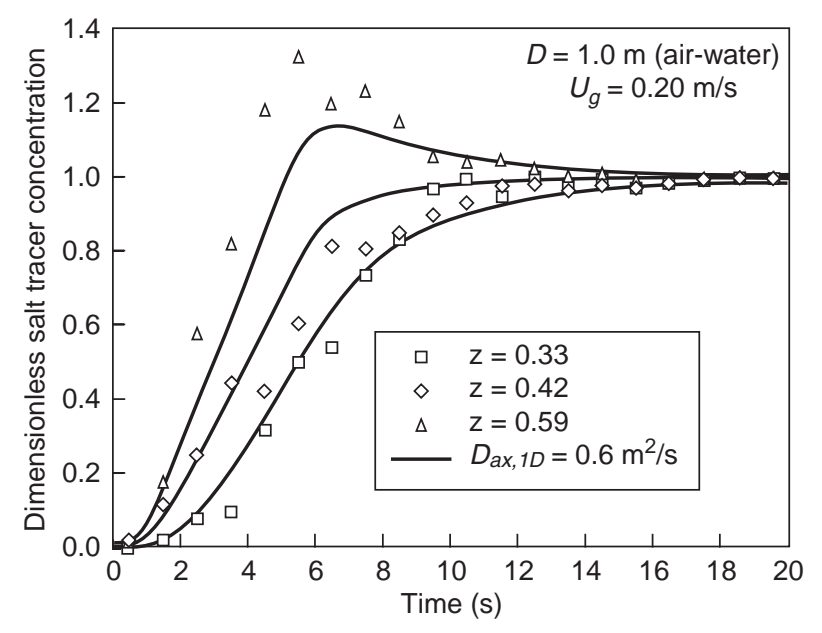

Figure 15

Tracer time responses at different heights and validation of the $\operatorname{ADM}\left(D=1 \mathrm{~m}\right.$, air-water system, $\left.U_{g}=0.20 \mathrm{~m} / \mathrm{s}\right)$.

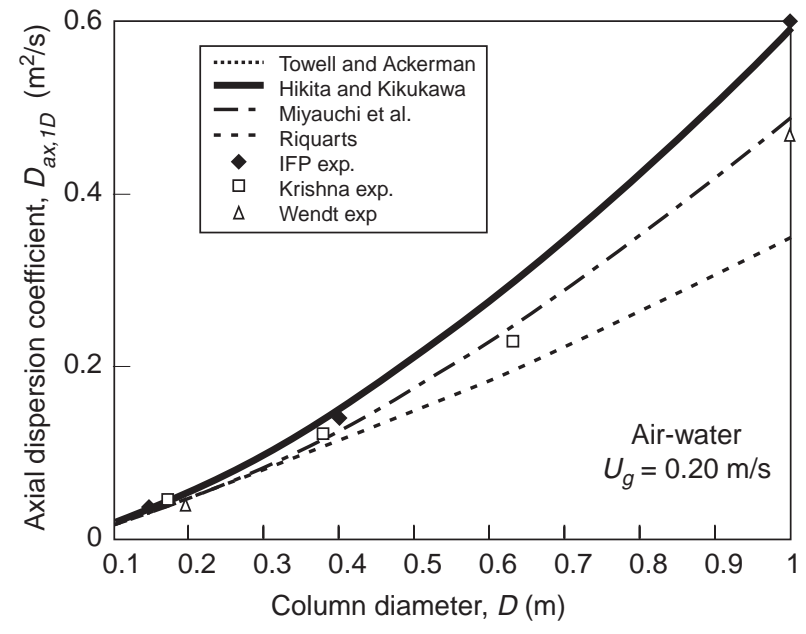

Figure 16

$D_{a x, l D}$ as a function of $D$ compared with empirical correlations. 


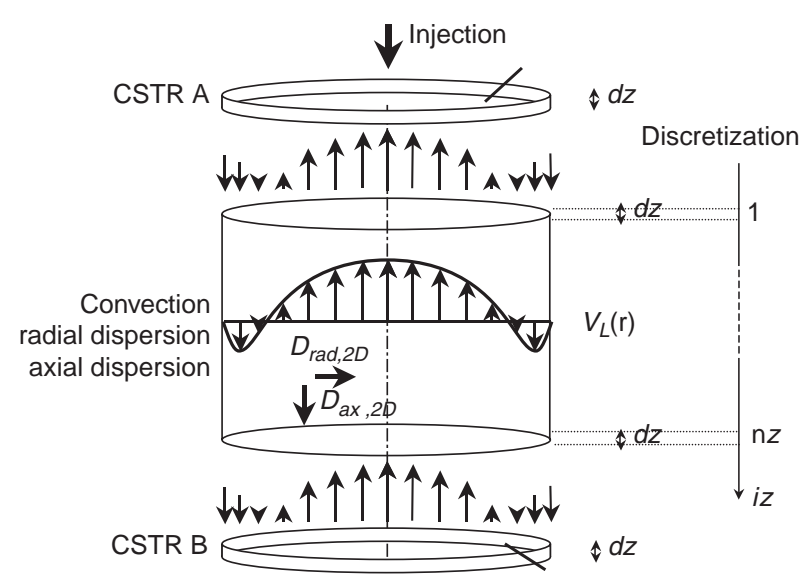

Figure 17

2-D model.

scale recirculation), axial dispersion $\left(D_{a x, 2 D}\right)$ and radial dispersion $\left(D_{\text {rad,2D }}\right)$ (see Fig. 17).

One of the main difference between the 1-D ADM and the 2-D model is that the axial convective recirculation and the dispersion contributions to liquid mixing are separated in the 2-D model, whereas they are lumped in the coefficient $D_{a x, 1 D}$ in the ADM. The concentration of the tracer $C^{L}$ in the liquid phase is given by:

$$
\begin{aligned}
\frac{\partial C^{L}}{\partial t} & =D_{a x, 2 D} \cdot \frac{\partial^{2} C^{L}}{\partial z^{2}}-V_{L}(r) \cdot \frac{\partial C^{L}}{\partial z} \\
& +\frac{D_{r a d, 2 D}}{\left(1-\varepsilon_{g}\right)} \cdot \frac{\partial}{\partial r}\left(\left(1-\varepsilon_{g}\right) \cdot \frac{\partial C^{L}}{\partial r}\right)+\frac{D_{r a d, 2 D}}{r} \cdot \frac{\partial C^{L}}{\partial r}
\end{aligned}
$$

where the radial profile of gas holdup and liquid velocity are determined experimentally. The boundary conditions consider that the reactor is closed to radial dispersion. In addition, in the region close to the free surface at the top of the column and in the distributor region, the flow pattern is quite complex. These regions are modeled by extremely thin CSTR (see Fig. 17). In other words we consider infinite mixing in these regions (both axial and radial) that constitutes a strong assumption. The concentration of the $\operatorname{tracer} C^{L}$ is then given by:

$$
\begin{aligned}
& \left(1-\bar{\varepsilon}_{g}\right) \cdot V_{C S T R A} \cdot \frac{\partial C_{A}}{\partial t}=K \cdot q_{i n j} \cdot C_{i n j}+\int_{0}^{r_{i n v}} 2 \pi r\left[1-\varepsilon_{g}(r)\right] \\
& \cdot V_{L}(r) \cdot C^{\mathrm{iz}=1} \cdot d r-\int_{r_{i n v}}^{r_{R}} 2 \pi r\left[1-\varepsilon_{g}(r)\right] \cdot V_{L}(r) \cdot C_{A} \cdot d r
\end{aligned}
$$

with $K=1$ for $t \leq t_{i n j}$ and $K=0$ for $\mathrm{t}>t_{i n j}$.

$$
\begin{aligned}
& \left(1-\bar{\varepsilon}_{g}\right) \cdot V_{C S T R B} \cdot \frac{\partial C_{B}}{\partial t}=\int_{0}^{r_{i n v}} 2 \pi r\left[1-\varepsilon_{g}(r)\right] \cdot V_{L}(r) \cdot C_{B} \cdot d r \\
& -\int_{r_{i n v}}^{r_{R}} 2 \pi r\left[1-\varepsilon_{g}(r)\right] \cdot V_{L}(r) \cdot C^{i z=n z} \cdot d r
\end{aligned}
$$

The 2D model simulations are first compared to the measurements without internals: cross-sectional averaged tracer time responses are used here. From the experimental set of data at $U_{g}=0.15 \mathrm{~m} / \mathrm{s}$, the best model adjustment is obtained with $D_{a x, 2 D} / D_{r a d, 2 D}=20$. We can note that, at this given superficial gas velocity, the cross-sectional averaged tracer time responses simulated by the $2 \mathrm{D}$ model are equivalent to responses simulated by the ADM with $D_{a x, 1 D}=0.5 \mathrm{~m}^{2} / \mathrm{s}$ (see Fig. 18a: cross-sectional averaged tracer time responses). Moreover, Figure 18b shows that the corresponding local

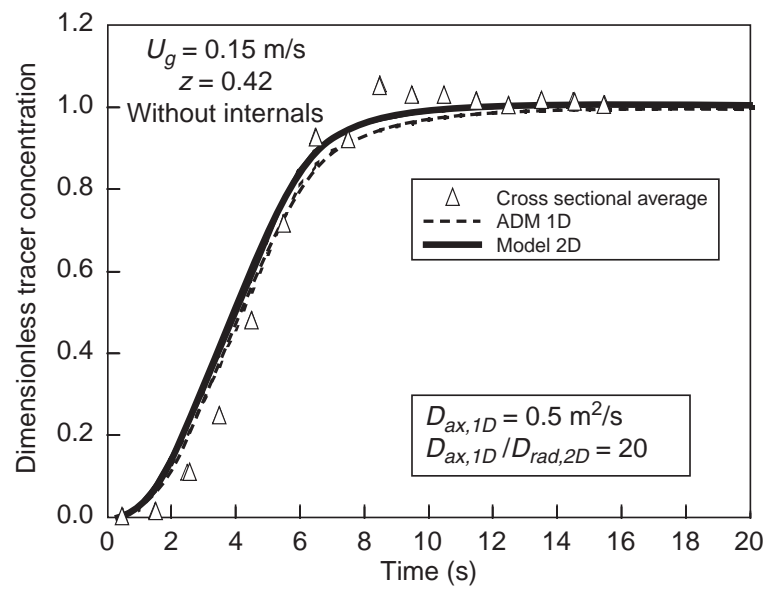

a)

Figure 18

a) Cross-sectional averaged and b) local tracer time responses without internals.

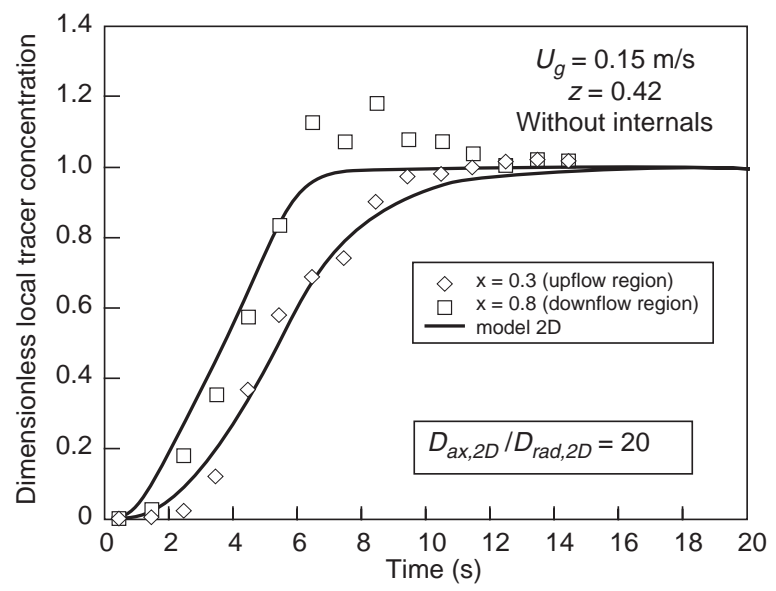

b) 
tracer time responses (in the upflow and in the downflow region) are in reasonably agreement with the $2 \mathrm{D}$ model local simulations.

Figure 19 represents snapshots simulated by the 2D model each second after the injection of the tracer at the top of the column in these conditions $\left(D=1 \mathrm{~m}, U_{g}=0.15 \mathrm{~m} / \mathrm{s}\right.$; $H_{D}=3.6 \mathrm{~m} ; D_{a x, 2 D} / D_{r a d, 2 D}=20$ ). The color blue corresponds to a tracer concentration nil, the red corresponds to the maximum concentration. The yellow corresponds to the final concentration i.e. when the tracer concentration is homogeneous all over the column.

As expected, the tracer flows first downwards along the column wall while it diffuses towards the centre-line; at about $t=7 \mathrm{~s}$, it spreads over the whole cross-section because it enters the inner upward flow. Note that the color at the outer sampling point $(x=0.85)$ is at most yellow which means that there is no concentration overshoot.

\subsection{Internals Effects on Liquid Mixing}

In the presence of internals, large scale recirculation is enhanced and the axial liquid velocity $V_{L}(r)$ increases in the core of the bed; the radial liquid velocity is negligible. Nevertheless, the normalized liquid velocity profile $V_{L}(r) / V_{L}(0)$ is not modified and remains constant: in the churn-turbulent regime (high gas velocity), the liquid flows upwards in the core region and downwards in the wall region. Even in the presence of internals, flow reversal still takes place at $x=0.7$ (Hills, 1974). Moreover, the presence of internals leads to a decrease of the r.m.s. fluctuation of the velocity $u_{\sigma}(r)$. Figure 20 shows radial profiles of the axial fluctuations of liquid velocity at a given superficial gas velocity of $0.15 \mathrm{~m} / \mathrm{s}$ in the core region.

We observe that the maximum of the fluctuations of velocity $u_{\sigma}$ is found at the inversion flow $(x=0.7)$. Degaleesan

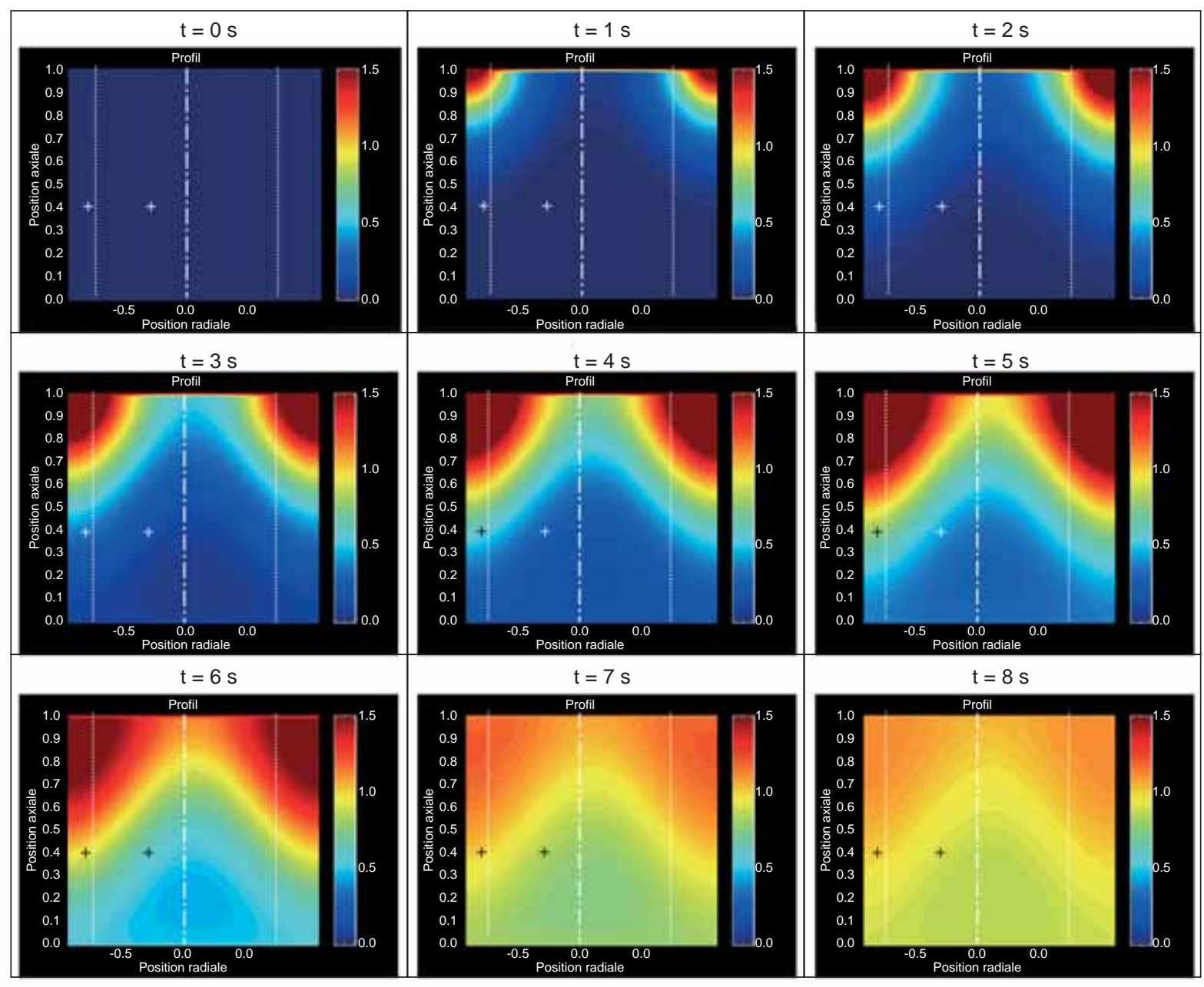

+: Sampling point

Figure 19

2-D model simulation for $D=1 \mathrm{~m}$ without internals $\left(U_{g}=0.15 \mathrm{~m} / \mathrm{s} ; H_{D}=3.6 \mathrm{~m} ; D_{a x, 2 D} / D_{r a d, 2 D}=20\right)$. 


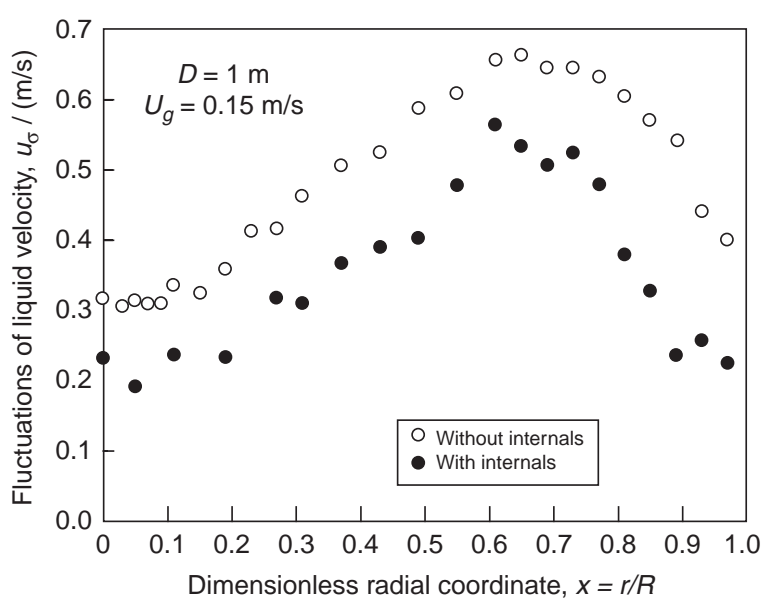

Figure 20

Radial profile of the fluctuations of velocity with and without internals.

et al. (1997) have also shown that the maximum axial eddy diffusivity occurs at a point which is close to the inversion point of liquid recirculation velocity, where the maximum turbulent shear stress occurs.

Modification of liquid recirculation pattern in the presence of internals leads to a change of liquid mixing. Indeed, liquid mixing is a resultant of global convective recirculation of the liquid phase (induced by the non-uniform gas radial holdup distribution), but also to the turbulent dispersion (due to the eddies generated by the rising bubbles) (Degaleesan et al., 1997). Since the large scale recirculation contribution to liquid backmixing is enhanced with internals, the ratio convection-dispersion is modified, and the one-dimensional ADM, validated without internals, is not appropriate anymore to large bubble columns with internals (see Fig. 21a): whatever the value of $D_{a x, 1 D}$, the 1D ADM is not able to reproduce the experimental data. Therefore, the adjustment of $2 \mathrm{D}$ model prediction with experimental data obtained at $U_{g}=0.15 \mathrm{~m} / \mathrm{s}$ with internals lead to the following model parameters (Figs 21a and b): $D_{a x, 2 D} / D_{r a d, 2 D}=400$.

The best fit obtained with internals is found with a significantly lower $D_{\mathrm{rad}, 2 D}$ than without internals. This trend is consistent with the decrease of the fluctuations of velocity observed experimentally (see Fig. 20). Contrarily to what was observed with the ADM, the $2 \mathrm{D}$ model is able to reproduce the transient concentration overshoot both for the crosssectional average (Fig. 21a) and local concentrations observed at $z=0.41$ with $H_{D}=3.7 \mathrm{~m}$ (Fig. $21 b$ ). The model parameters $D_{a x, 2 D}$ and $D_{r a d, 2 D}$ should not only be linked to large scale recirculation (time-averaged liquid velocity) but also to the fluctuations of velocity. Figure 22 represents snapshots simulated by the $2 \mathrm{D}$ model each second after the injection of tracer in these conditions $\left(D=1 \mathrm{~m}, U_{g}=0.15 \mathrm{~m} / \mathrm{s} ; H_{D}=3.7 \mathrm{~m}\right.$; $\left.D_{a x, 2 D} / D_{r a d, 2 D}=400\right)$.

Comparing to Figure 19, we observe that with internals tracer flows down at the wall more rapidly, and remains stuck on the wall (lower radial dispersion). Then, it enters into the upward flow region earlier than without internals. At $t=8 \mathrm{~s}$, a significant radial concentration gradient is still present contrarily to simulations without internals (see Fig. 19). The color at both the outer and inner sampling points reaches the red level before leveling off at the yellow level. This is reflected by the concentration overshoot observed in Figure 21b. Finally, the delay between concentration maxima reflects the large recirculation time. The recirculation of tracer is more pronounced with internals, due to enhancement of the convective contribution and decrease of the dispersion effect (decrease of the fluctuations of velocities)

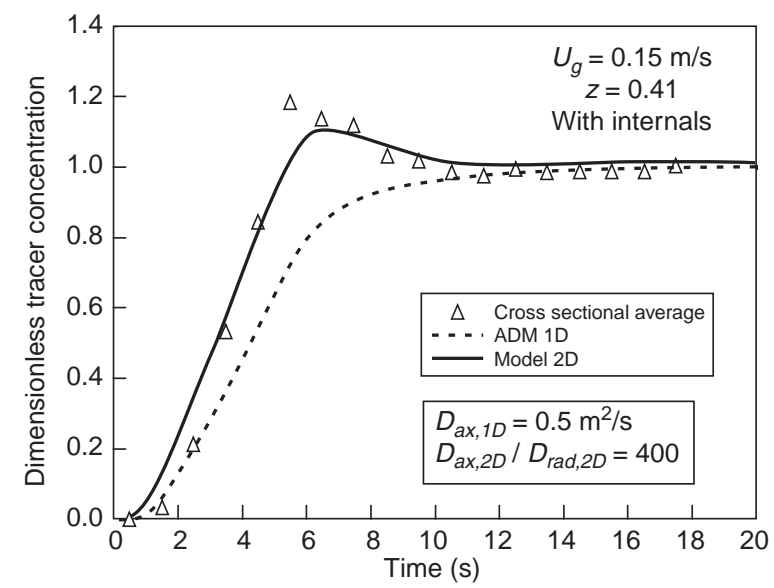

a)

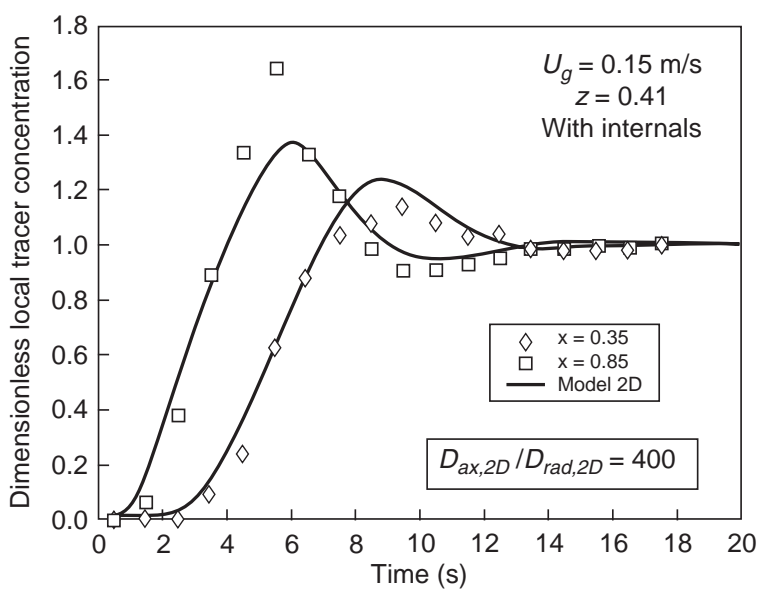

b)

Figure 21

a) Cross-sectional averaged and b) local tracer time responses with internals. 


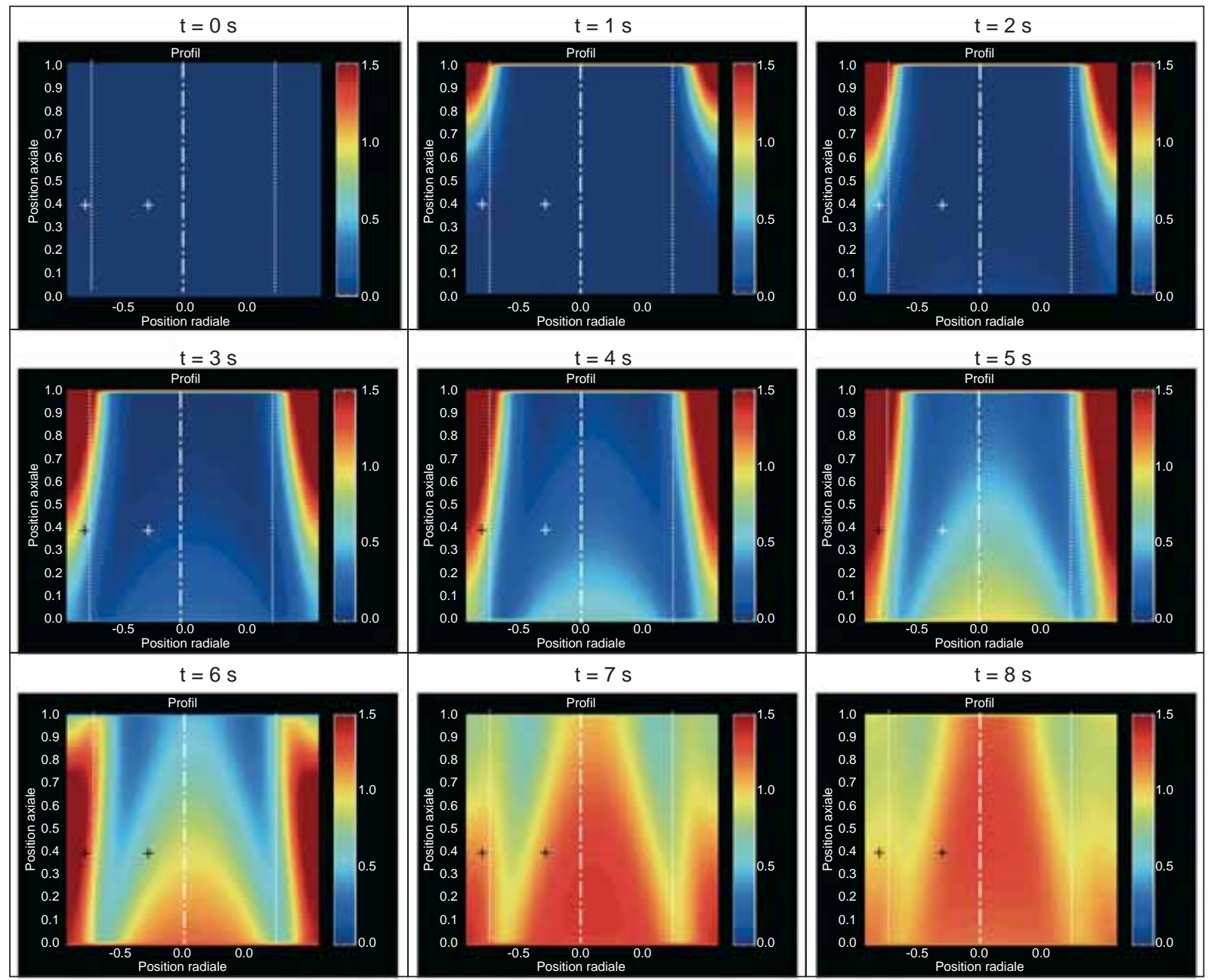

+: Sampling point

Figure 22

2-D model simulation for $D=1 \mathrm{~m}$ with internals $\left(U_{g}=0.15 \mathrm{~m} / \mathrm{s} ; H_{D}=3.7 \mathrm{~m} ; D_{a x, 2 D} / D_{\text {rad }, 2 D}=400\right)$.

\section{CONCLUSION}

Hydrodynamic characteristics of a slurry bubble column are not affected by the reactor aspect ratio provided aerated height to diameter ratio $H_{D} / D$ greater than 5 . In these conditions:

- The normalized profiles $\varepsilon_{g}(x) / \bar{\varepsilon}_{g}$ and $V_{L}(x) / V_{L}(0)$ are independent of column diameter and gas flowrate, and are well described respectively by normalized profile equations in the following conditions:

. column diameters $D>0.15 \mathrm{~m}$ (wall effect negligible);

. in the stabilized region (say $1 D$ above distributor and $1 D$ below the free surface);

. in the churn-turbulent regime (no effect of distributor design).

Thus, $\bar{\varepsilon}_{g}$ and $V_{L}(0)$ are key parameters in describing bubble columns flow pattern, even in the presence or not of internals.
- Global gas holdup is not affected by column diameter (provided $D>0.15 \mathrm{~m}$ ).

- Mixing of the slurry phase results from two distinct physical processes: large scale recirculations, essentially axial, resulting from the upward and downward flow regions; and turbulence, or the fluctuations of velocity, that contributes both to radial and axial mixing. The presence of internals affects these two processes: internals enhance convection (increase of time-averaged liquid velocity) and decrease fluctuating motion.

- The one dimensional axial dispersion model, appropriate in bubble columns without internals is insufficient to describe mixing in bubble columns with internals.

Our study has enabled to highlight scale effect on the hydrodynamics of slurry bubble columns and to evaluate scale up trends. 


\section{REFEREN CES}

Baird, M.H. and Rice, R.G. (1975) Axial Dispersion in Large Unbaffled Columns. Chem. Eng. J., 9, 171-174.

Berg, S. and Schlüter, S. (1995) Rückvermischung in blasensäulen mit einbauten. Chem. Ing. Tech., 67, 3, 289-299.

Bernemann, K. (1989) Zur fluiddynamik und zum vermischungsverhalten der flüssigen phase in blasensäulen mit längsangeströmten rohrbündeln (Hydrodynamics of the Liquid Phase in Bubble Columns with internals). Dissertation, Universität Dortmund.

Bukur, D.B., Patel, S.A. and Matheo, R. (1987) Hydrodynamic Studies in Fischer-Tropsch Derived Waxes in a Bubble Column. Chem. Eng. Comm., 60, 63-78.

Deckwer, W.D., Louisi, Y., Zaidi, A. and Ralek, M. (1980) Hydrodynamic Properties of the Fischer-Tropsch Slurry Process. Ind. Eng. Chem. Proc. Des. Dev., 19, 699-708.

Degaleesan, S., Dudukovic, M.P., Toseland, B.A. and Bhatt, B.L. (1997) A Two-Compartment Convective-Diffusion Model for Slurry Bubble Column Reactors. Ind. Eng. Chem. Res., 36, 46704680 .

Devanathan, N. (1991) Investigation of Liquid Hydrodynamics in Bubble Columns via a Computer Automated Radioactive Particle Tracking (CARPT). Ph.D. Thesis, Washington University, Saint Louis, Missouri, USA.

Fischer, F. and Tropsch, H. (1921) Synthesis of Methanol from $\mathrm{CO}$ and $\mathrm{H}_{2}$. French Patent 540, 543.

Forret, A., Schweitzer, J.M., Gauthier, T., Krishna, R. and Schweich, D. (2003) Influence of Scale on the Hydrodynamics of Bubble Column Reactors: An Experimental Study in Columns of 0.1,0.4 and $1 \mathrm{~m}$ Diameters. Chem. Eng. Sci., 58, 719-724.

Geary, N.W. and Rice, R.G. (1992) Circulation and Scale-Up in Bubble Columns. AIChE J., 38, 1, 76-82.

Hills, J.H. (1974) Radial Non-Uniformity of Velocity and Voidage in a Bubble Column. Trans. Inst. Chem. Eng., 52, 1-9.

Joshi, J.B., Parasu Veera, U., Prasad, Ch.V., Phanikumar, D.V., Deshphande, N.S., Thakre, S.S. and Thorat, B.N. (1998) Gas Hold-Up Structure in Bubble Column Reactors. PINSA Review article, 64, A, 4, 441-567.

Joshi, J.B. (2001) Computational Flow Modelling and Design of Bubble Column Reactors. Chem. Eng. Sci., 56, 5893-5933.

Kawase, Y. and Moo-Young, M. (1989) Turbulence Intensity in Bubble Columns. Chem. Eng. J., 40, 1, 55-58.

Kojima, E., Unno, H., Sato, Y., Chida, T., Imai, H., Endo, K., Inoue, I., Kobayashi, J., Kaji, H., Nakanishi, H. and Yamamoto, K. (1980) Liquid Phase Velocity in a $5.5 \mathrm{~m}$ Diameter Bubble Column. Journal of Chemical Engineering of Japan, 13, 1, 16-21.

Krishna, R. and Ellenberger, J. (1996) Gas Holdup in Bubble Column Reactors Operating in the Churn-Turbulent Regime. AIChE J., 42, 2627-2634

Krishna, R, Ellenberger, J. and Sie, S.T. (1996) Reactor Development for Conversion of Natural Gas to Liquid Fuels: a ScaleUp Strategy Relying on Hydrodynamics Analogies. Chem. Eng. Sci., 51, 5041-2050.
Krishna, R., Urseanu, M.I., Van Baten, J.M. and Ellenberger, J. (1999) Influence of Scale on the Hydrodynamics of Bubble Columns Operating in the Churn-Turbulent Regime: Experiments vs. Eulerian Simulations. Chem. Eng. Sci., 54, 4903-4911.

Krishna, R. (2000) A Scale-up Strategy for a Commercial Scale Bubble Column Slurry Reactor for Fischer-Tropsch Synthesis. Oil \& Gas Science and Technology - Rev. IFP, 55, 4, 359-393.

Krishna R. and Sie. S.T. (2000) Selection, Design and Scale-Up Aspects of Fischer-Tropsch Reactors. Fuel Processing Technology, 64, 73-105.

Levenspiel, O. and Fitzgerald, T.J. (1983) A Warning on the Misuse of the Dispersion Model. Chem. Eng. Sci., 38, 489.

Luo, X., Lee, D.J., Lau, R., Yang, G.Q. and Fan, L.S. (1999) Maximum Stable Bubble Size and Gas Holdup in High-pressure Slurry Bubble Columns. AIChE J., 45, 4, 665-680.

Miyauchi, T. and Shyu, C.N. (1970) Flow of Fluid in Gas Bubble Columns. Kagaku Kogaku, 34, 958-964.

Nottenkämper, R., Steiff, A. and Weinspach, P.M. (1983) Experimental Investigation of Hydrodynamics of Bubble Columns. Ger. Chem. Eng., 6, 147-155.

Parasu Veera, U. and Joshi, J.B. (2000) Measurement of Gas Holdup Profiles in Bubble Column by Gamma Ray Tomography, Effect of Liquid Phase Properties. Trans IChemE, 78, Part A, 425-434.

Patel, S.A., Daly, J.G. and Bukur, D.B. (1990) Bubble-Size Distribution in Fischer-Tropsch Derived Waxes in Bubble Column. AIChE J., 36, 1, 93-105.

Riquarts, H.P. (1981) A Physical Model for Axial Mixing of the Liquid Phase for Heterogeneous Flow Regime in Bubble Columns. German Chemical Engineering, 4, 18-23.

Schweitzer, J.M., Bayle, J. and Gauthier, T. (2001) Local Gas Hold-Up Measurements in Fluidized Bed and Slurry Bubble Column. Chem. Eng. Sci., 56, 1103-1110.

Shah, Y.T., Kelkar, B.G., Godbole, S.P. and Deckwer, W.D. (1982) Design Parameters Estimations for Bubble Column Reactors. AIChE J., 28, 353-379.

Towell, G.D. and Ackerman, G.H. (1972) Axial Mixing of Liquid and Gas in Large Bubble Reactors. Proceeding of 2nd International Symposium Chem. React. Eng., Amsterdam, The Netherlands, B3.1-B3.13.

Ueyama, K. and Miyauchi, T. (1979) Properties of Recirculating Turbulent Two Phase Flow in Gas Bubble Columns. AIChE J., 25, 2, 258-266.

Urseanu, M.I. (2000) Scaling Up Bubble Column Reactors. Ph.D. Thesis, University of Amsterdam, The Netherlands.

Wen, C.Y. and Fan, L.T. (1975) Models for Flow Systems and Chemical Reactors, Dekker, New York.

Wendt, R., Steiff, A. and Weinspach, P.M. (1984) Liquid Phase Dispersion in Bubble Columns. Ger. Chem. Eng., 7, 267-273.

Zehner, P. (1986) Momentum, Mass and Heat Transfer in Bubble Columns, Part 1: Flow Model of the Bubble Column and Liquid Velocities. Int. Chem. Eng., 41, 1969-1977.

Final manuscript received in January 2006

Copyright (C) 2006 Institut français du pétrole

Permission to make digital or hard copies of part or all of this work for personal or classroom use is granted without fee provided that copies are not made or distributed for profit or commercial advantage and that copies bear this notice and the full citation on the first page. Copyrights for components of this work owned by others than IFP must be honored. Abstracting with credit is permitted. To copy otherwise, to republish, to post on servers, or to redistribute to lists, requires prior specific permission and/or a fee: Request permission from Documentation, Institut français du pétrole, fax. +33147527078 , or revueogst@ifp.fr. 